\title{
Study on Mechanical Characteristics of Fully Grouted Rock Bolts for Underground Caverns under Seismic Loads
}

\author{
Guoqing Liu, ${ }^{1,2}$ Ming Xiao, ${ }^{1,2}$ Juntao Chen, ${ }^{1,2}$ and Hao Zhou ${ }^{1,2}$ \\ ${ }^{1}$ State Key Laboratory of Water Resources and Hydropower Engineering Science, Wuhan University, Wuhan 430072, China \\ ${ }^{2}$ Key Laboratory of Rock Mechanics in Hydraulic Structural Engineering of Ministry of Education, Wuhan University, \\ Wuhan 430072, China \\ Correspondence should be addressed to Ming Xiao; mxiao@whu.edu.cn
}

Received 13 November 2016; Revised 21 January 2017; Accepted 15 February 2017; Published 16 March 2017

Academic Editor: Roman Wendner

Copyright (C) 2017 Guoqing Liu et al. This is an open access article distributed under the Creative Commons Attribution License, which permits unrestricted use, distribution, and reproduction in any medium, provided the original work is properly cited.

\begin{abstract}
This study establishes an analytical model for the interaction between the bolt and surrounding rock based on the bearing mechanism of fully grouted rock bolts. The corresponding controlled differential equation for load transfer is deduced. The stress distributions of the anchorage body are obtained by solving the equations. A dynamic algorithm for the bolt considering shear damage on the anchoring interface is proposed based on the dynamic finite element method. The rationality of the algorithm is verified by a pull-out test and excavation simulation of a rounded tunnel. Then, a case study on the mechanical characteristics of the bolts in underground caverns under seismic loads is conducted. The results indicate that the seismic load may lead to stress originating from the bolts and damage on the anchoring interface. The key positions of the antiseismic support can be determined using the numerical simulation. The calculated results can serve as a reference for the antiseismic optimal design of bolts in underground caverns.
\end{abstract}

\section{Introduction}

Southwestern China is a region characterized by high mountains, rolling hills, and abundant water resources. Many hydropower stations have been established or are under construction in this region. Restricted by geological conditions, these hydropower stations are mainly built across underground rocks, and many large-scale underground caverns have been formed. The region is located at plate boundaries with a high probability of earthquakes, and its seismic fortification intensity is generally above VII. The antiseismic performance of underground caverns is directly related to the safe operation of hydropower stations. With the application of the New Austrian Tunneling Method, bolt support has been the most widely used as a flexible reinforcement measure. Bolting static design theory has been increasingly maturing. However, still there is not a full understanding of the joint mechanisms between rock bolts and the surrounding rock and the dynamic response characteristics of the bolts under seismic loads. Therefore, establishing a reasonable dynamic analytical model and developing an efficient numerical calculation platform for the bolt are of great significance for analyzing the antiseismic stability of underground caverns.

As one of the main approaches for bolt support in underground caverns, fully grouted rock bolts have shown excellent performance in reinforcing the rock. Currently, researchers mainly focus on the force of the bolt. Recent research on basic mechanical transform mechanisms between the bolt and medium is mainly based on pull-out tests, including establishing theoretical models $[1-8]$ and performing tests [9-11]. However, the mechanical characteristics of the bolt in practical engineering projects are considerably different from those in observed pull-out tests. Freeman [12] and Wang et al. [13] first proposed the neutral point theory, which has been widely used for underground caverns. Many scholars have studied the action mechanism between the bolt and rock in tunnels based on this theory and obtained theoretical solutions [14-18] for the stress distribution of the bolt. However, these methods are mainly suitable for single cavern featuring a simple structure. Numerical methods should be 


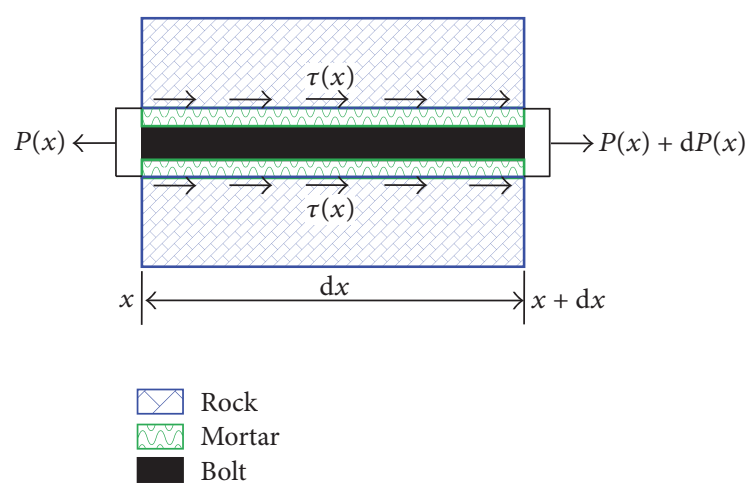

FIGURE 1: Interaction between the bolt and rock.

studied for large-scale groups of underground caverns under complex geological conditions.

Few studies have presented dynamic calculations for bolts to date. Xue et al. [19] analyzed the influence of seismic loading on bolts using FLAC and obtained the variation of the axial force of the bolt with dynamic loading times. Zhang and Xiao [20] proposed an algorithm that was suitable for antiseismic analysis to simulate bolts based on the numerical algorithm adopted by FLAC3D. However, these algorithms neglect the inhomogeneity of the stress distribution of the bolt and do not focus on damage evolution properties of the anchoring interface during earthquakes.

This paper proposes a new analytical algorithm for the interaction between the bolt and rock considering shear damage on the anchoring interface under a seismic load based on the bearing mechanism of fully grouted rock bolts in underground caverns. The rationality of the algorithm is verified; then, the dynamic response of an engineering case is evaluated. Several meaningful conclusions are obtained.

\section{Analytical Model for the Interaction between the Bolt and Rock}

Engineering practice shows that slip separation of the anchorage body is a common failure mode of bolts. Therefore, the following basic assumptions were made to study the interaction between the bolt and rock. (1) The bolt is made of a linear-elastic material, and only the axial deformation is considered. (2) The perfect combination between the bolt and mortar causes them to deform together. (3) The slip failure of the bolt occurs only on the contact interface between the anchorage body and rock.

A one-dimensional local coordinate system was established along the axial direction of the bolt, whose positive direction points to the deep rock from the anchor head. A small piece of the anchorage body was taken for study, whose coordinate is $x$ and length is $\mathrm{d} x$, as shown in Figure 1. The basic mechanical equations can be expressed as follows.

The balanced differential equation is

$$
\mathrm{d} P(x)+2 \pi r_{\mathrm{a}} \tau(x) \mathrm{d} x=0 .
$$

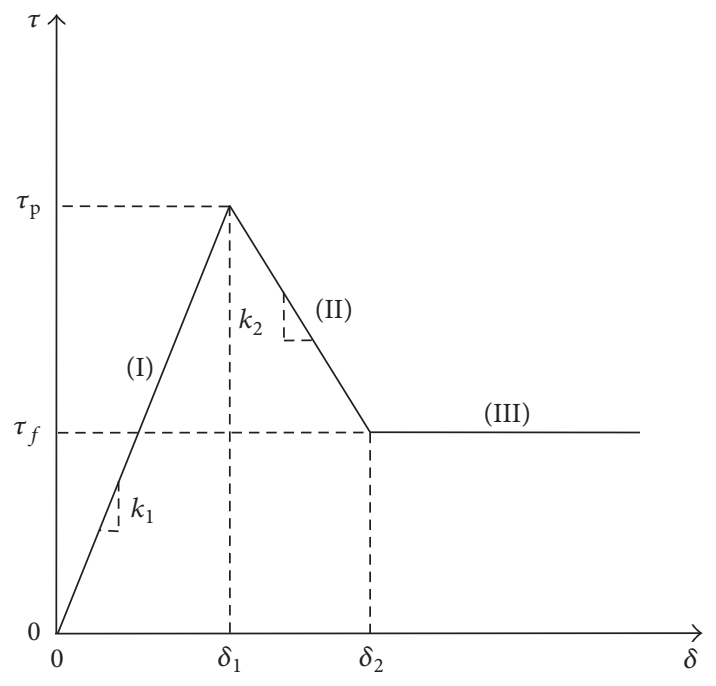

FIGURE 2: Trilinear shear slip model.

The constitutive equation is

$$
\varepsilon_{\mathrm{a}}(x)=\frac{\sigma(x)}{E_{\mathrm{a}}}=\frac{P(x)}{\pi E_{\mathrm{a}} r_{\mathrm{a}}{ }^{2}} .
$$

The geometric equation is

$$
\varepsilon_{\mathrm{a}}(x)=\frac{\mathrm{d} u_{\mathrm{a}}(x)}{\mathrm{d} x},
$$

where $P(x)$ and $\sigma(x)$ are the axial force and normal stress of the anchorage body at $x$, respectively. $\tau(x)$ is the shear stress of the anchoring interface. $\varepsilon_{\mathrm{a}}(x)$ and $u_{\mathrm{a}}(x)$ are the axial strain and axial displacement of the anchorage body, respectively. $r_{\mathrm{a}}$ is the radius of the anchorage body. $E_{\mathrm{a}}$ is the composite elastic modulus of the anchorage body.

The controlled equation for the interaction between the bolt and rock can be obtained by combining (1)-(3):

$$
\frac{\mathrm{d}^{2} u_{\mathrm{a}}(x)}{\mathrm{d} x^{2}}+\frac{2}{E_{\mathrm{a}} r_{\mathrm{a}}} \tau(x)=0 .
$$

Supposing that the axial displacement of the rock at $x$ is $u_{\mathrm{r}}(x)$, the shearing relative displacement between the rock and anchorage body is $\delta(x)=u_{\mathrm{r}}(x)-u_{\mathrm{a}}(x)$. The trilinear shear slip model [21] was adopted to describe the relationship between $\tau(x)$ and $\delta(x)$, as shown in Figure 2. The unified expression is

$$
\tau(x)=k \delta(x)+c .
$$

The values of $k$ and $c$ are determined according to three different stages.

(I) Elastic Stage. The shear stress increases proportionately with the relative displacement, and there is no damage on the anchoring interface.

$$
\begin{aligned}
k & =k_{1}, \\
c & =0,
\end{aligned}
$$


where $k_{1}$ is the shear stiffness of the anchoring interface during the elastic stage, which is calculated by the following equation:

$$
k_{1}=\frac{k_{\mathrm{r}} k_{\mathrm{m}}}{k_{\mathrm{r}}+k_{\mathrm{m}}},
$$

where $k_{\mathrm{r}}$ is the shear stiffness of the rock. $k_{\mathrm{r}}$ is $5-10 \mathrm{GPa} / \mathrm{m}$ for hard rock and $1.5-3 \mathrm{GPa} / \mathrm{m}$ for soft rock. $k_{\mathrm{m}}$ is the shear stiffness of the mortar and is determined by [22]

$$
k_{\mathrm{m}}=\frac{G_{\mathrm{m}}}{r_{\mathrm{a}} \operatorname{In}\left(1+t / r_{\mathrm{b}}\right)},
$$

where $G_{\mathrm{m}}$ is the shear modulus of the mortar, $r_{\mathrm{b}}$ is the radius of the bolt, and $t$ is the thickness of the mortar.

(II) Plastic Softening Stage. The shear stress proceeds in the opposite direction when the relative displacement increases, and partial damage exists on the anchoring interface.

$$
\begin{aligned}
& k=k_{2}, \\
& c=\frac{\tau_{\mathrm{p}} \delta_{2}-\tau_{f} \delta_{1}}{\delta_{2}-\delta_{1}},
\end{aligned}
$$

where $\delta_{1}$ and $\delta_{2}$ are the relative displacements corresponding to the peak shear strength and the end of the softening stage, respectively, and $k_{2}$ is the shear stiffness of the anchoring interface during the softening stage. $\tau_{\mathrm{p}}$ is the peak shear strength of the anchoring interface, which meets the MohrCoulomb yield condition:

$$
\tau_{\mathrm{p}}=c_{j}+\sigma_{\mathrm{r}} \tan \varphi_{j},
$$

where $c_{j}$ and $\varphi_{j}$ are the cohesive force and internal frictional angle of the anchoring interface, respectively, and $\sigma_{\mathrm{r}}$ is the hydrostatic confining pressure of the rock perpendicular to the anchorage body.

(III) Slip Stage. The shear stress remains the same when the relative displacement increases, and the anchoring interface suffers extensive damage.

$$
\begin{aligned}
& k=0, \\
& c=\tau_{f},
\end{aligned}
$$

where $\tau_{f}$ is the residual shear strength of the anchoring interface, which is written as

$$
\tau_{f}=\sigma_{\mathrm{r}} \tan \varphi_{j} .
$$

Substituting (5) into (4) yields

$$
\frac{\mathrm{d}^{2} u_{\mathrm{a}}(x)}{\mathrm{d} x^{2}}+\frac{2 k}{E_{\mathrm{a}} r_{\mathrm{a}}}\left[u_{\mathrm{r}}(x)-u_{\mathrm{a}}(x)\right]+\frac{2 c}{E_{\mathrm{a}} r_{\mathrm{a}}}=0 .
$$

Equation (13) is the controlled equation for the interaction between the bolt and rock considering shear damage on the anchoring interface.
The damage coefficient, $D$, is defined to describe the shear damage degree at different parts of the anchoring interface and is calculated by

$$
D= \begin{cases}0, & \left(0 \leq \delta \leq \delta_{1}\right), \\ \frac{\delta-\delta_{1}}{\delta_{2}-\delta_{1}}, & \left(\delta_{1}<\delta \leq \delta_{2}\right) \\ 1, & \left(\delta>\delta_{2}\right) .\end{cases}
$$

The value of $D$ ranges from 0 to $1 . D=0,0<D<1$, and $D=1$ correspond to states (I), (II), and (III), respectively.

\section{Solution for the Stress of the Bolt Based on the Finite Difference Method}

Equation (13) is a second-order linear differential equation with constant coefficients. It is difficult to obtain the functional expression of $u_{\mathrm{a}}(x)$ using analytical methods. The finite difference method was adopted in this paper to acquire the numerical solution of $u_{\mathrm{a}}(x)$.

Supposing that the bolt length is $L$, the anchorage body is divided into $N$ equal segments, and each segment length is $\Delta L=L / N$. The segmented points from $x=0$ to $x=L$ are numbered in order as $1,2, \ldots, N+1$. Then, the values of $u_{\mathrm{r}}(x)$ and $u_{\mathrm{a}}(x)$ at the $i$ th segmented point can be expressed as $u_{\mathrm{r}}{ }^{i}$ and $u_{\mathrm{a}}{ }^{i}$, respectively. The variables $k_{i}$ and $c_{i}$ represent the material constants of the anchoring interface at the $i$ th segmented point. According to the finite difference method, (13) can be discretized as follows.

When $i=1$,

$$
\frac{u_{\mathrm{a}}^{2}-u_{\mathrm{a}}{ }^{1}}{\Delta L^{2}}+\frac{k_{1}}{E_{\mathrm{a}} r_{\mathrm{a}}}\left(u_{\mathrm{r}}{ }^{1}-u_{\mathrm{a}}{ }^{1}\right)+\frac{c_{1}}{E_{\mathrm{a}} r_{\mathrm{a}}}=0 .
$$

When $2 \leq i \leq N$,

$$
\frac{u_{\mathrm{a}}^{i+1}-2 u_{\mathrm{a}}^{i}+u_{\mathrm{a}}^{i-1}}{\Delta L^{2}}+\frac{2 k_{i}}{E_{\mathrm{a}} r_{\mathrm{a}}}\left(u_{\mathrm{r}}^{i}-u_{\mathrm{a}}^{i}\right)+\frac{2 c_{i}}{E_{\mathrm{a}} r_{\mathrm{a}}}=0 .
$$

When $i=N+1$,

$$
\frac{u_{\mathrm{a}}{ }^{N}-u_{\mathrm{a}}{ }^{N+1}}{\Delta L^{2}}+\frac{k_{N+1}}{E_{\mathrm{a}} r_{\mathrm{a}}}\left(u_{\mathrm{r}}^{N+1}-u_{\mathrm{a}}^{N+1}\right)+\frac{c_{N+1}}{E_{\mathrm{a}} r_{\mathrm{a}}}=0 .
$$

Equations (15)-(17) can be rewritten in the matrix form as

$$
[A]\left[u_{\mathrm{a}}\right]=[B]\left[u_{\mathrm{r}}\right]+[D],
$$

where 


$$
\begin{aligned}
& {[A]=\left[\begin{array}{cccc}
a_{1} & 2 h & & \\
h & a_{2} & h & \\
\ddots & \ddots & \ddots & \\
& h & a_{N} & h \\
& & 2 h & a_{N+1}
\end{array}\right]} \\
& \sigma_{i}= \begin{cases}E_{\mathrm{a}} \frac{u_{\mathrm{a}}^{2}-u_{\mathrm{a}}{ }^{1}}{\Delta L}, & (i=1), \\
E_{\mathrm{a}} \frac{u_{\mathrm{a}}^{i+1}-u_{\mathrm{a}}^{i-1}}{2 \Delta L}, & (2 \leq i \leq N), \\
E_{\mathrm{a}} \frac{u_{\mathrm{a}}^{N+1}-u_{\mathrm{a}}{ }^{N}}{\Delta L}, & (i=N+1),\end{cases} \\
& P_{i}=\pi r_{\mathrm{a}}{ }^{2} \sigma_{i} \quad(1 \leq i \leq N+1) .
\end{aligned}
$$$$
[B]=\left[\begin{array}{ccccc}
b_{1} & & & & \\
& b_{2} & & & \\
& & \ddots & & \\
& & b_{N} & \\
& & & b_{N+1}
\end{array}\right]
$$$$
\left[u_{\mathrm{a}}\right]=\left[\begin{array}{c}
u_{\mathrm{a}}{ }^{1} \\
u_{\mathrm{a}}^{2} \\
\vdots \\
u_{\mathrm{a}}{ }^{N+1}
\end{array}\right]
$$$$
\left[u_{\mathrm{r}}\right]=\left[\begin{array}{c}
u_{\mathrm{r}}^{1} \\
u_{\mathrm{r}}^{2} \\
\vdots \\
u_{\mathrm{r}}{ }^{N+1}
\end{array}\right]
$$$$
[D]=\left[\begin{array}{c}
d_{1} \\
d_{2} \\
\vdots \\
d_{N+1}
\end{array}\right]
$$$$
h=-\frac{1}{2 \Delta L^{2}},
$$$$
a_{i}=\frac{1}{\Delta L^{2}}+\frac{k_{i}}{E_{\mathrm{a}} r_{\mathrm{a}}},
$$$$
b_{i}=\frac{k_{i}}{E_{\mathrm{a}} r_{\mathrm{a}}}
$$$$
d_{i}=\frac{c_{i}}{E_{\mathrm{a}} r_{\mathrm{a}}} .
$$

When $\left[u_{\mathrm{r}}\right]$ is known, (18) becomes a tridiagonal linear equations system for the unknown variable $\left[u_{\mathrm{a}}\right]$, which can be solved using the speedup method.

The values of $\tau(x), \sigma(x)$, and $P(x)$ at different segmented points are calculated by

$$
\tau_{i}=k_{i}\left(u_{\mathrm{r}}^{i}-u_{\mathrm{a}}^{i}\right)+c_{i} \quad(1 \leq i \leq N+1),
$$

Based on the same deformation of the bolt and mortar, the normal stress, $\sigma_{\mathrm{b}}(x)$, and axial force, $P_{\mathrm{b}}(x)$, of the bolt are obtained as

$$
\begin{aligned}
& \sigma_{\mathrm{b}}(x)=\frac{E_{\mathrm{b}}}{E_{\mathrm{a}}} \sigma(x), \\
& P_{\mathrm{b}}(x)=\frac{E_{\mathrm{b}} r_{\mathrm{b}}{ }^{2}}{E_{\mathrm{a}} r_{\mathrm{a}}{ }^{2}} P(x) .
\end{aligned}
$$

\section{Dynamic Finite Element Calculation under Bolt Support}

Regarding the dynamic finite element calculation for underground caverns under bolt support, the central difference method was mainly used to solve the differential equation of motion as follows [20]:

$$
M \ddot{a}=f_{\text {ext }}+f_{\mathrm{mg}}-f_{\mathrm{int}}-f_{\mathrm{damp}},
$$

where $M$ is the lumped mass of the nodes of the finite element model, $\ddot{a}$ is the acceleration of the nodes, $f_{\text {ext }}$ and $f_{\text {int }}$ are the external and internal forces of the nodes, respectively, $f_{\text {damp }}$ is the damping force of the nodes, and $f_{\mathrm{mg}}$ is the support reaction force offered by the bolts, which can be calculated by the following method.

Having learned the action results for the seismic load under bolt support at $t_{n-1}$, the free deformation calculation of the rock without support was conducted first at $t_{n}$. This process can be described by solving the following differential equation of motion:

$$
M \ddot{a}=f_{\text {ext }}-f_{\text {int }}-f_{\text {damp }} .
$$

The rock displacement at all segmented points of the bolt in the global coordinate system is obtained according to the interpolation theory of the finite element shape function. Then, the axial displacement of the rock at segmented points can be acquired by projecting the displacement in the vector direction of the bolt. Substituting $\left[u_{\mathrm{r}}\right]$ into (18) yields $\left[u_{\mathrm{a}}\right]$. Having acquired $\left[u_{\mathrm{a}}\right]$ and $\left[u_{\mathrm{r}}\right]$, the functional relationship between $\tau(x)$ and $\delta(x)$ can be redefined and the matrices $[A]$, $[B]$, and $[D]$ can be renewed.

The bolts can restrict the rock deformation by providing a support reaction force. The shear stress of the anchoring interface can be equivalently transformed into the concentrated loads of the segmented points. Then, the concentrated loads are exerted on the rock elements in a contrary direction, which can simulate the anchoring effect of the bolts. Supposing that the shear stress of each segment 
of the bolt is linearly distributed, the equivalent load of each segmented point is expressed as

$$
T_{i}=\pi r_{\mathrm{a}} \Delta L\left(\tau_{i}+\tau_{i+1}\right),
$$

where $T_{i}$ is the equivalent load of the $i$ th segmented point: $i=1,2, \ldots, N$.

The three components of $T_{i}$ in the global coordinate system are given as

$$
\left[\begin{array}{lll}
T_{i}^{x} & T_{i}^{y} & T_{i}^{z}
\end{array}\right]^{\mathrm{T}}=\left[\begin{array}{lll}
l & m & n
\end{array}\right]^{\mathrm{T}} T_{i},
$$

where $l, m$, and $n$ are the directional cosines of the bolt.

According to the interpolation theory of the shape function, the support reaction force exerted on the rock by the $i$ th segmented point is deduced by

$$
f_{\mathrm{mg}}=P_{j}^{k}=-N_{j} T_{i}^{k},
$$

where $P_{j}{ }^{k}$ is the support reaction force at the $j$ th node of the rock element in the $x, y$, and $z$ directions, $N_{j}$ is the value of the shape function at the $j$ th node of the element at the segmented point, and $T_{i}^{k}$ represents the three components of $T_{i}$ in the global coordinate system.

Iterating this process for all of the bolts yields the total support reaction force of the rock system. The rock displacement is updated by solving (24). Several iterations were repeated according to the steps above, and the convergent solution of the rock displacement can be obtained, which will help to obtain the internal force of the anchorage body. The detailed calculation procedure is shown in Figure 3.

\section{Verification of the Numerical Model}

The rationality of the analytical model for the bolt was verified by assessing two static calculation examples before the dynamic calculation was conducted.

5.1. Example 1. During the pull-out test, the bolt is subjected to a tensile load, and the rock or concrete is approximately fixed; that is, $\left[u_{\mathrm{r}}\right]=0$. Then, (15) is modified as

$$
\frac{1}{\Delta L^{2}} u_{\mathrm{a}}{ }^{2}-\left(\frac{1}{\Delta L^{2}}+\frac{k_{1}}{E_{\mathrm{a}} r_{\mathrm{a}}}\right) u_{\mathrm{a}}{ }^{1}+\frac{c_{1}}{E_{\mathrm{a}} r_{\mathrm{a}}}=\frac{P_{0}}{\pi r_{\mathrm{a}}{ }^{2} E_{\mathrm{a}} \Delta L},
$$

where $P_{0}$ is the tensile load.

Therefore, (18) can be rewritten as

$$
[A]\left[u_{\mathrm{a}}\right]=[D],
$$

where the meanings of $[A],\left[u_{\mathrm{a}}\right]$, and $[D]$ are the same as above and $d_{1}=c_{1} /\left(E_{\mathrm{a}} r_{\mathrm{a}}\right)-P_{0} /\left(\pi r_{\mathrm{a}}^{2} E_{\mathrm{a}} \Delta L\right)$.

In this example, the bolt was buried directly in the concrete. The physical and mechanical parameters of the bolt and anchoring interface are provided in Table 1. Supposing that there is no damage on the interface of the bolt, $k_{i}=k_{1}$, $c_{i}=0$, and $i=1,2, \ldots, N+1$. The matrix $\left[u_{\mathrm{a}}\right]$ in (30) can be calculated directly without iterations.

The normal stress distributions of the bolt for $P_{0}=100 \mathrm{kN}$ and $P_{0}=150 \mathrm{kN}$ were calculated by using the bolt algorithm
TABLE 1: Physical and mechanical parameters.

\begin{tabular}{lccc}
\hline & Bolt & \multicolumn{2}{c}{ Interface } \\
\hline$E_{\mathrm{b}}$ & $210 \mathrm{GPa}$ & $k_{1}$ & $25 \mathrm{GPa} / \mathrm{m}$ \\
$\mu_{\mathrm{b}}$ & 0.3 & & \\
$L$ & $1 \mathrm{~m}$ & & \\
$r_{\mathrm{b}}$ & $16 \mathrm{~mm}$ & & \\
\hline
\end{tabular}

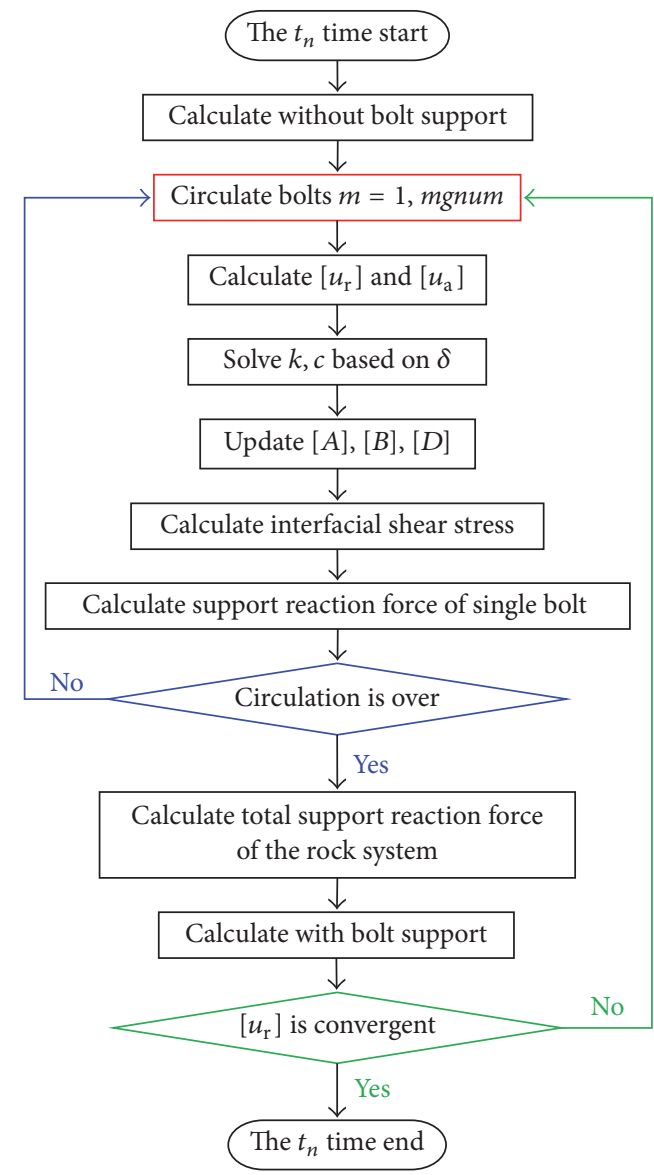

FIGURE 3: Flowchart of the dynamic finite element calculation for the anchoring system at $t_{n}$.

in this paper and referring to the tests from Rong et al. [9], as shown in Figure 4.

The numerical values of the normal stress are nearly consistent with those of the experimental results, except for a slight difference in the quantity. The difference is smaller when $P_{0}=100 \mathrm{kN}$ because there is only minor damage on the anchoring interface under smaller loads, and the interfacial shear stiffness was considered to remain constant during the experiment. For $P_{0}=150 \mathrm{kN}$, the difference is slightly larger because more damage occurs on the anchoring interface under larger loads. The interfacial shear stiffness was reduced during the experimental process but is thought to remain constant in the numerical simulation, which leads to 
TABLE 2: Physical and mechanical parameters.

\begin{tabular}{|c|c|c|c|c|c|c|c|}
\hline \multicolumn{2}{|c|}{ Rock } & \multicolumn{2}{|c|}{ Mortar } & \multicolumn{2}{|c|}{ Bolt } & \multicolumn{2}{|c|}{ Interface } \\
\hline$E_{\mathrm{r}}$ & $4 \mathrm{GPa}$ & $E_{\mathrm{m}}$ & $10 \mathrm{GPa}$ & $E_{\mathrm{b}}$ & $210 \mathrm{GPa}$ & $c_{j}$ & $0.6 \mathrm{MPa}$ \\
\hline$k_{\mathrm{r}}$ & $3 \mathrm{GPa} / \mathrm{m}$ & $\mu_{\mathrm{m}}$ & 0.167 & $\mu_{\mathrm{b}}$ & 0.3 & $\varphi_{j}$ & $25^{\circ}$ \\
\hline$\mu_{\mathrm{r}}$ & 0.3 & $t$ & $10 \mathrm{~mm}$ & $L$ & $2.5 \mathrm{~m}$ & & \\
\hline$c_{\mathrm{r}}$ & $0.8 \mathrm{MPa}$ & & & $r_{\mathrm{b}}$ & $11 \mathrm{~mm}$ & & \\
\hline$\varphi_{\mathrm{r}}$ & $30^{\circ}$ & & & Space & $1.05 \mathrm{~m} \times 1.2 \mathrm{~m}$ & & \\
\hline
\end{tabular}

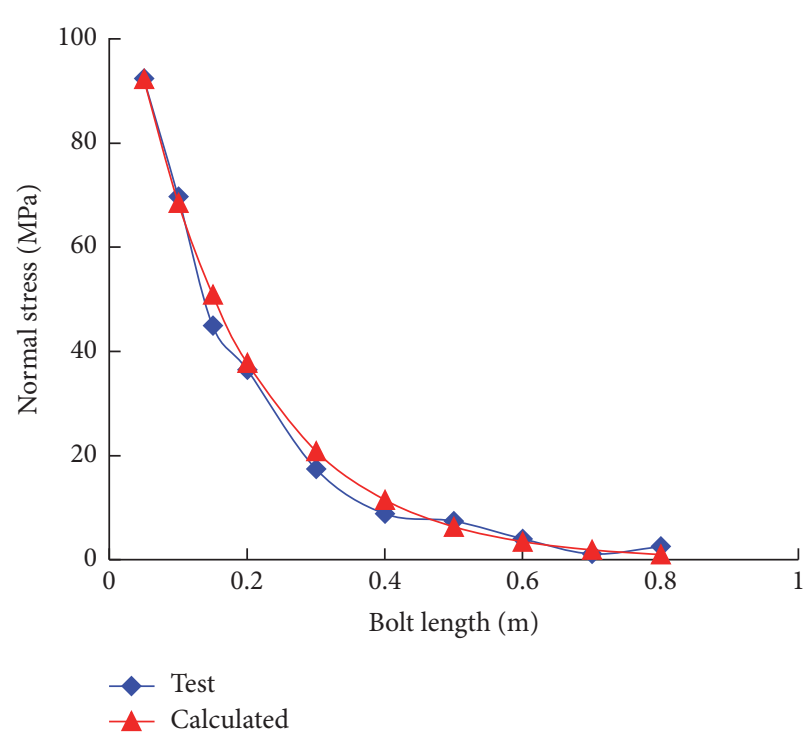

(a) $P_{0}=100 \mathrm{kN}$

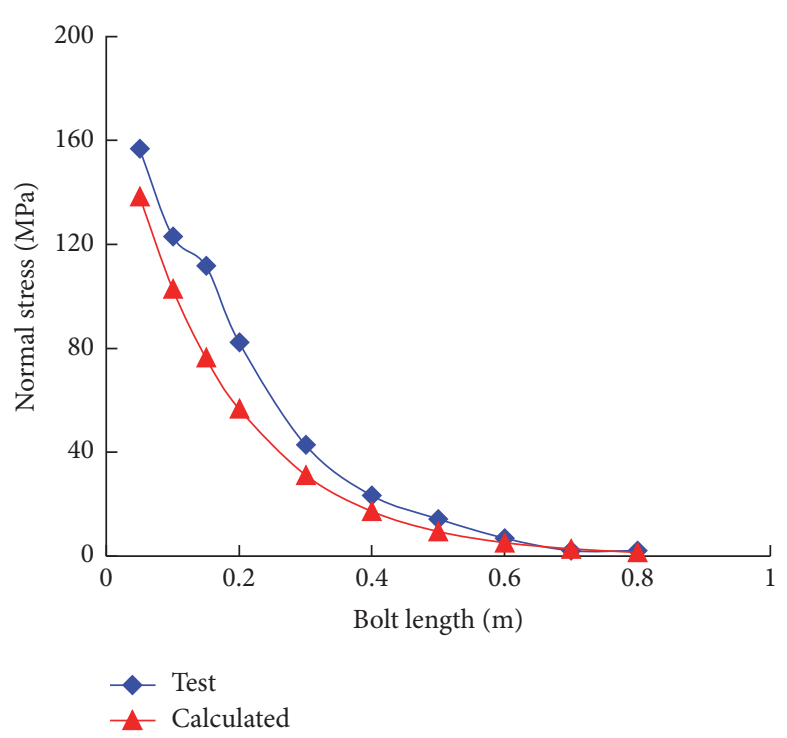

(b) $P_{0}=150 \mathrm{kN}$

FIGURE 4: Normal stress distributions of the bolt.

the smaller values in the simulation calculation than those of the experiment.

5.2. Example 2. Example 2 was derived from a deeply buried rounded tunnel with an excavation radius of $5 \mathrm{~m}$ [16]. The physical and mechanical parameters of the materials are provided in Table 2. A bolt at the top arch was monitored to observe its force state. The stress distributions of the bolt when the tunnel was excavated were obtained, as illustrated in Figure 5.

The shear stress is characterized by positive and negative values. Negative values indicate that the direction of the shear stress points to the free face of the cavern from 0 to $0.7 \mathrm{~m}$, whereas positive values indicate that the direction of the shear stress points to the deep rock from 0.7 to $2.5 \mathrm{~m}$. The location where the shear stress equals 0 is the location where the axial force is maximal, which corresponds with the neutral point theory.

Three monitoring points were set at $0.25,1.25$, and $2.25 \mathrm{~m}$ along the bolt length. The measured values and calculated values of the axial force are compared in Figure 5. The calculated values of the axial force derived from the three monitoring points show a closer match with the measured values, indicating the high accuracy of the bolt algorithm.

Therefore, the bolt algorithm proposed in this paper can reasonably reflect the factual bearing characteristics of the bolt during the pull-out test and in underground caverns. That is, the algorithm can satisfy the basic requirements for dynamic analysis.

\section{Engineering Case Study}

6.1. Engineering Profile and Calculation Model. The Wudongde hydropower station is characterized by powerhouses located separately on the left and right banks of the Jinsha River. The underground powerhouse on the left bank includes 6 hydroelectric generating sets. The size of the main powerhouse is $310.0 \mathrm{~m} \times 30.0 \mathrm{~m} \times 84.2 \mathrm{~m}$ (length $\times$ width $\times$ height) A three-dimensional finite element model consisting of 119,028 nodes and 112,905 elements of an 8-node hexahedron was built, as shown in Figure 6, which includes the diversion tunnel, main powerhouse, busbar chamber, main transformer room, tailrace tunnel, and surge shaft. The maximal characteristic mesh size was limited to less than $10 \mathrm{~m}$, which 


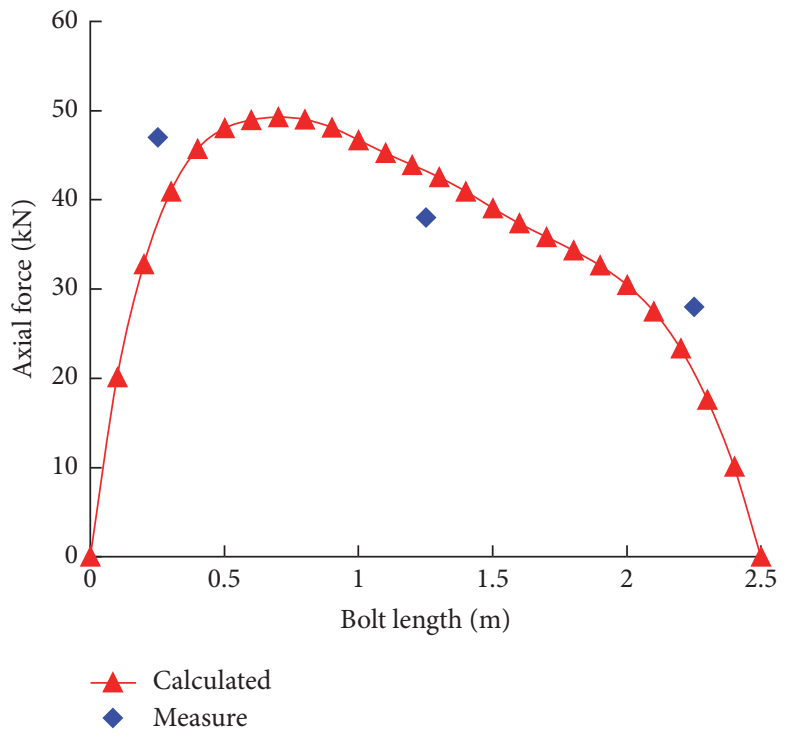

(a) Axial force distribution of the bolt

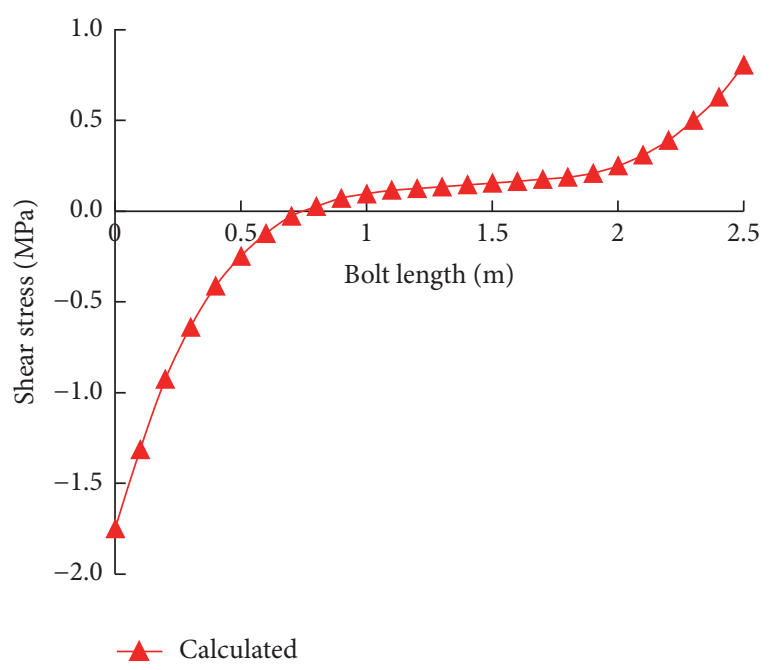

(b) Shear stress distribution of the anchoring interface

FIGURE 5: Stress distributions of the bolt.

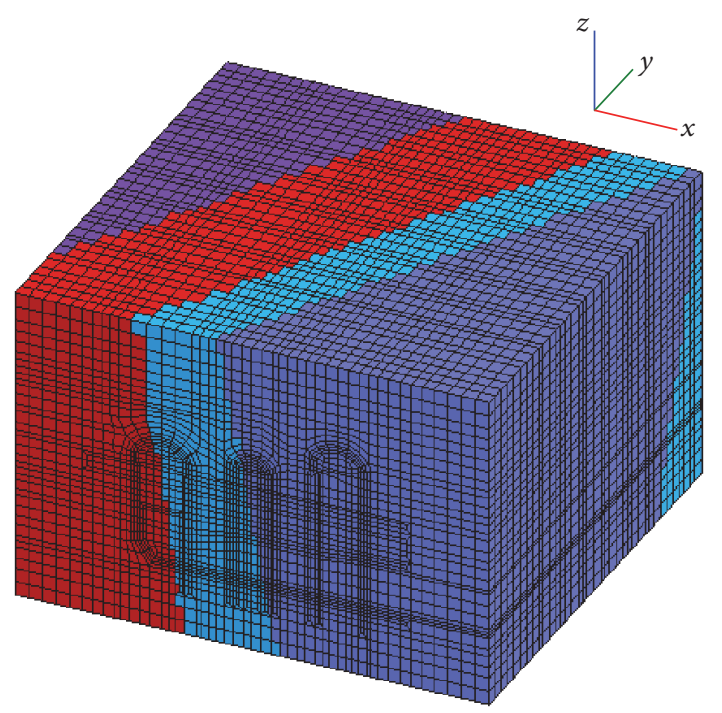

Rock

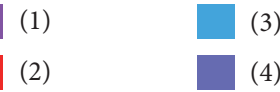

Figure 6: Calculation model.

satisfies the dynamic simulation requirement. The calculation ranges of the $x, y$, and $z$ directions were $360.3 \mathrm{~m}, 350.0 \mathrm{~m}$, and $247.1 \mathrm{~m}$, respectively. The excavation model is shown in Figure 7.

6.2. Calculation Conditions. The three-dimensional elastoplastic dynamic damaged displayed finite element program

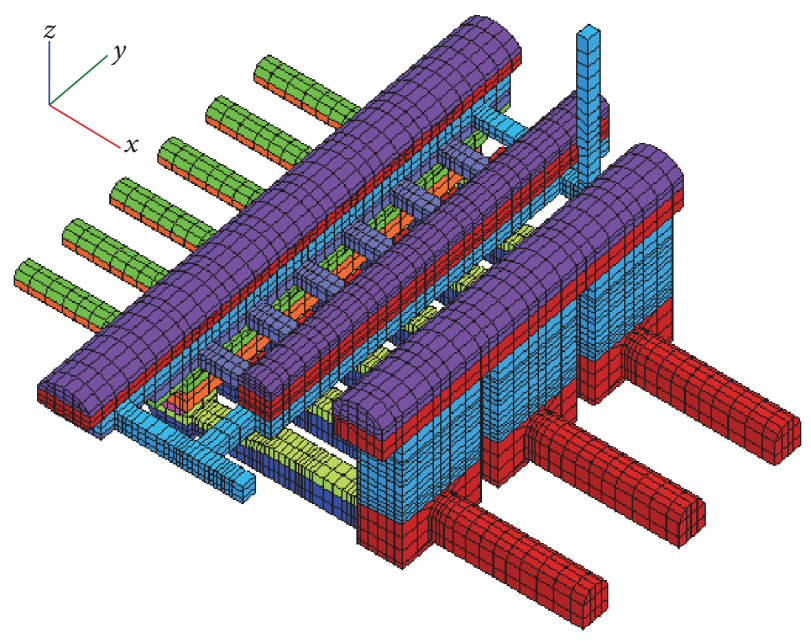

Excavation stage

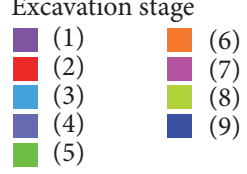

Figure 7: Excavation model.

[23] is adopted to analyze the seismic response of underground caverns. The initial three-dimensional geostress field is captured by stress inversion of the measured points. The disturbing stress field after the excavation of the caverns is taken as the initial condition for the dynamic calculation. The bolts in the main powerhouse are arranged alternately according to $@ 1.5 \mathrm{~m} \times 1.5 \mathrm{~m}, L=6 \mathrm{~m} / 9 \mathrm{~m}$. The bolts in the 
TABLE 3: Physical and mechanical parameters.

\begin{tabular}{|c|c|c|c|c|c|c|c|c|c|c|c|c|c|}
\hline \multicolumn{2}{|c|}{ Rock 1} & \multicolumn{2}{|c|}{ Rock 2} & \multicolumn{2}{|c|}{ Rock 3} & \multicolumn{2}{|c|}{ Rock 4} & \multicolumn{2}{|c|}{ Mortar } & \multicolumn{2}{|c|}{ Bolt } & \multicolumn{2}{|c|}{ Interface } \\
\hline$E_{\mathrm{r}}$ & $15 \mathrm{GPa}$ & $E_{\mathrm{r}}$ & $21.5 \mathrm{GPa}$ & $E_{\mathrm{r}}$ & $17.5 \mathrm{GPa}$ & $E_{\mathrm{r}}$ & $21.5 \mathrm{GPa}$ & $E_{\mathrm{m}}$ & $10 \mathrm{GPa}$ & $E_{\mathrm{b}}$ & $210 \mathrm{GPa}$ & $c_{j}$ & $0.8 \mathrm{MPa}$ \\
\hline$k_{\mathrm{r}}$ & $5 \mathrm{GPa} / \mathrm{m}$ & $k_{\mathrm{r}}$ & $5 \mathrm{GPa} / \mathrm{m}$ & $k_{\mathrm{r}}$ & $5 \mathrm{GPa} / \mathrm{m}$ & $k_{\mathrm{r}}$ & $5 \mathrm{GPa} / \mathrm{m}$ & $\mu_{\mathrm{m}}$ & 0.167 & $\mu_{\mathrm{b}}$ & 0.3 & $\varphi_{j}$ & $30^{\circ}$ \\
\hline$\mu_{\mathrm{r}}$ & 0.26 & $\mu_{\mathrm{r}}$ & 0.24 & $\mu_{\mathrm{r}}$ & 0.25 & $\mu_{\mathrm{r}}$ & 0.24 & $t$ & $8 \mathrm{~mm}$ & $r_{\mathrm{b}}$ & $14 \mathrm{~mm}$ & & \\
\hline$c_{\mathrm{r}}$ & $1.3 \mathrm{MPa}$ & $c_{\mathrm{r}}$ & $1.6 \mathrm{MPa}$ & $c_{\mathrm{r}}$ & $1.3 \mathrm{MPa}$ & $c_{\mathrm{r}}$ & $1.6 \mathrm{MPa}$ & & & $f_{\mathrm{b}}$ & $300 \mathrm{MPa}$ & & \\
\hline$\varphi_{\mathrm{r}}$ & $47.7^{\circ}$ & $\varphi_{\mathrm{r}}$ & $52.4^{\circ}$ & $\varphi_{\mathrm{r}}$ & $47.7^{\circ}$ & $\varphi_{\mathrm{r}}$ & $52.4^{\circ}$ & & & & & & \\
\hline
\end{tabular}

Note. $f_{\mathrm{b}}$ is the yield strength of the bolt.

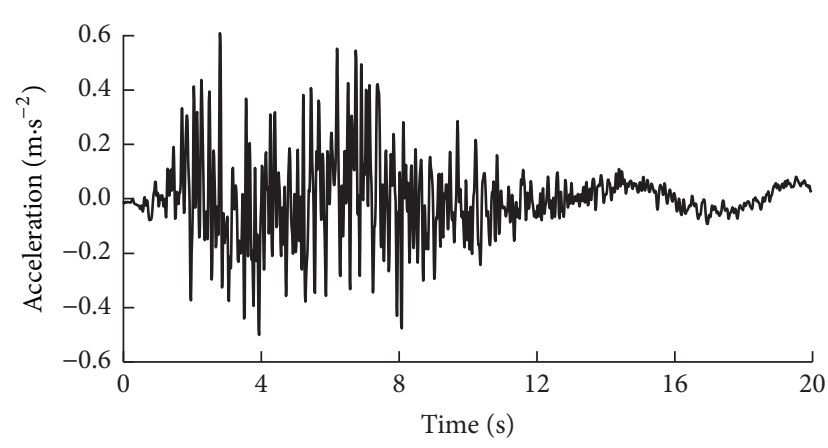

FIgURE 8: Time-history curve of the seismic acceleration.

main transformer room are arranged according to @1.5 $\mathrm{m} \times$ $1.5 \mathrm{~m}, L=6 \mathrm{~m}$. The physical and mechanical parameters of the materials are provided in Table 3 .

The engineering project is in a frequently earthquakestricken area whose basic seismic intensity is VII. The seismic wave was imported from the bottom of the model. The $x$ direction acceleration time-history is shown in Figure 8, and the $z$ direction acceleration time-history is $2 / 3$ that of the $x$ direction.

The viscous-elastic artificial boundary was applied at the bottom and top of the model, and the free field artificial boundary was applied at the other sides. The partial damping was adopted as 0.157 for the rock.

6.3. Analysis of the Calculation Results. Five monitoring bolts were arranged at five different positions of the mid-section of the 3 numbered unit sections to observe the force changes of the bolts during the earthquake, as shown in Figure 9.

6.3.1. Force Analysis of the Bolts before the Earthquake. The stress distributions of the monitoring bolts after all of the excavation stages were completed are plotted in Figure 10.

The stress distributions conform to the neutral point theory, as shown in Figure 10. The maximal normal stress appeared at the neutral point, whereas the shear stress at both ends of the bolts reached the maximum value. The stresses of the bolts at the top arches were significantly smaller than those at the sidewalls, whereas the maximal normal stress and shear stress of the bolts at the sidewalls did not exceed the yield strength and peak shear strength, respectively. That is, the bolts were in good contact with the rock.

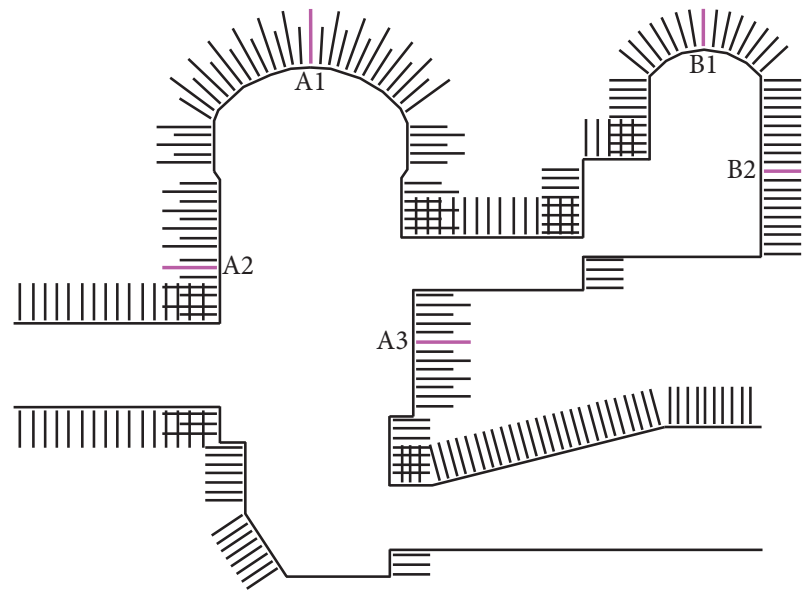

FIGURE 9: Layout of the monitoring bolts.

6.3.2. Force Time-History of the Bolts under Seismic Loads. The time-history curves of the maximal normal stress and shear stress at the anchor head of the monitoring bolts during the earthquake are plotted in Figure 11.

The maximal normal stress grew consistently over time when under the seismic load. The maximal normal stresses of the bolts at the sidewalls in the main powerhouse changed considerably as their values increased by $102 \mathrm{MPa}$ and $125 \mathrm{MPa}$ after the earthquake. The seismic load had a considerable influence on the force of the bolts. The main interpretation of this result is that the rock maintained a long state of stress adjustment during the earthquake, and the unrecoverable plastic deformation accumulated continuously over time. This led to the continuous growing strain of the bolts, whereas the majority of the bolts were in the plastic zone of the rock.

The shear stress at the anchor head initially increased gradually over time. Then, damage on the anchoring interface at the sidewalls in the main powerhouse occurred when the shear stress reached the peak shear strength. As the damage accumulated over time, the shear stress decreased slowly.

6.3.3. Force Analysis of the Bolts after the Earthquake. The stress distributions of the monitoring bolts when the seismic load was completed are plotted in Figure 12.

The stress distribution laws along the bolt length remained similar to those in Figure 10, except that the stress 


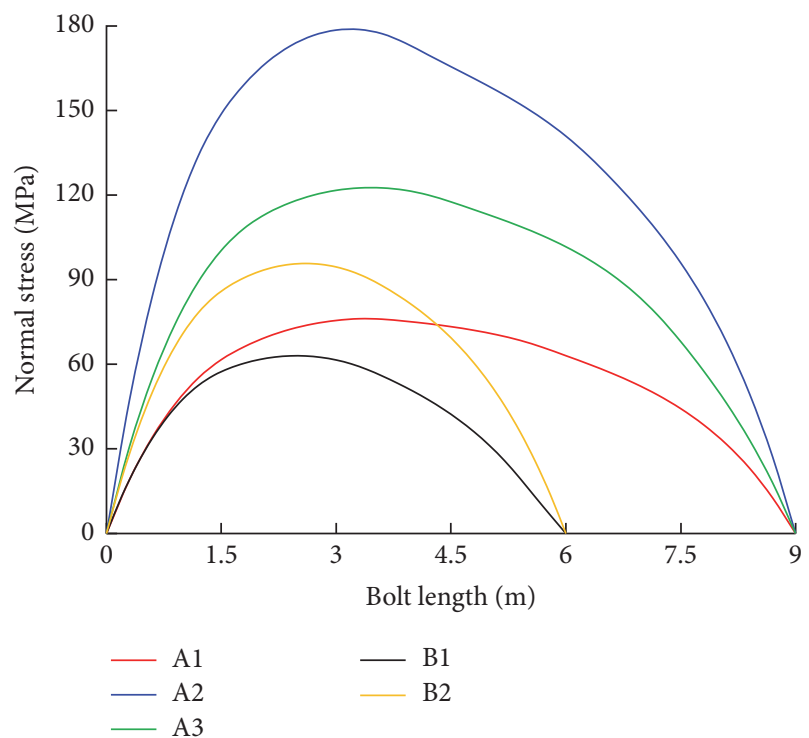

(a) Normal stress distributions of the bolts

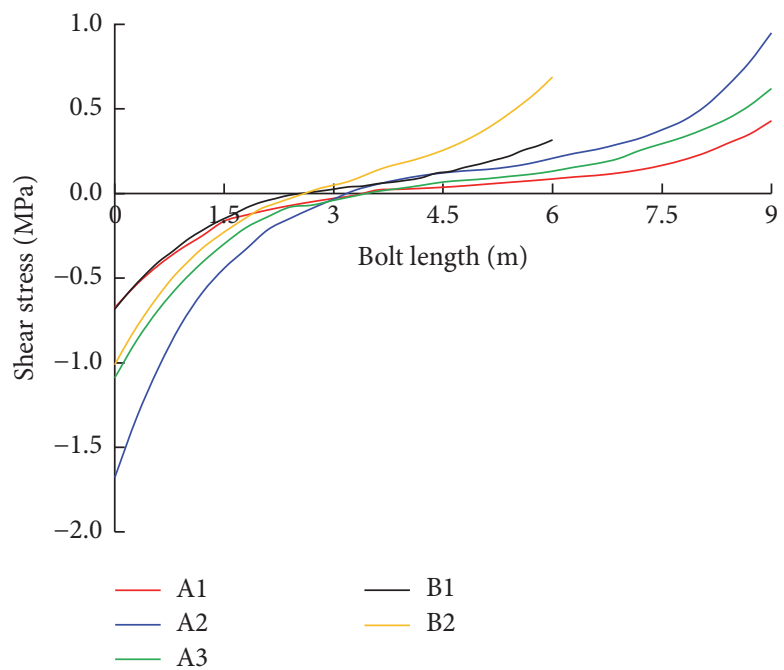

(b) Shear stress distributions of the anchoring interface

FIGURE 10: Stress distributions of the monitoring bolts (before the earthquake).

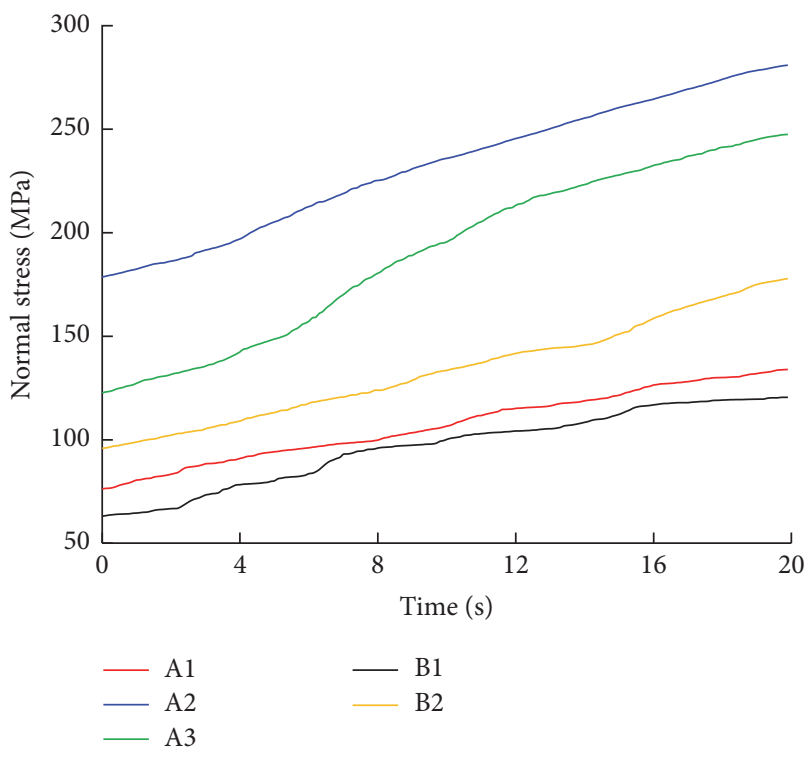

(a) Maximal normal stress time-history

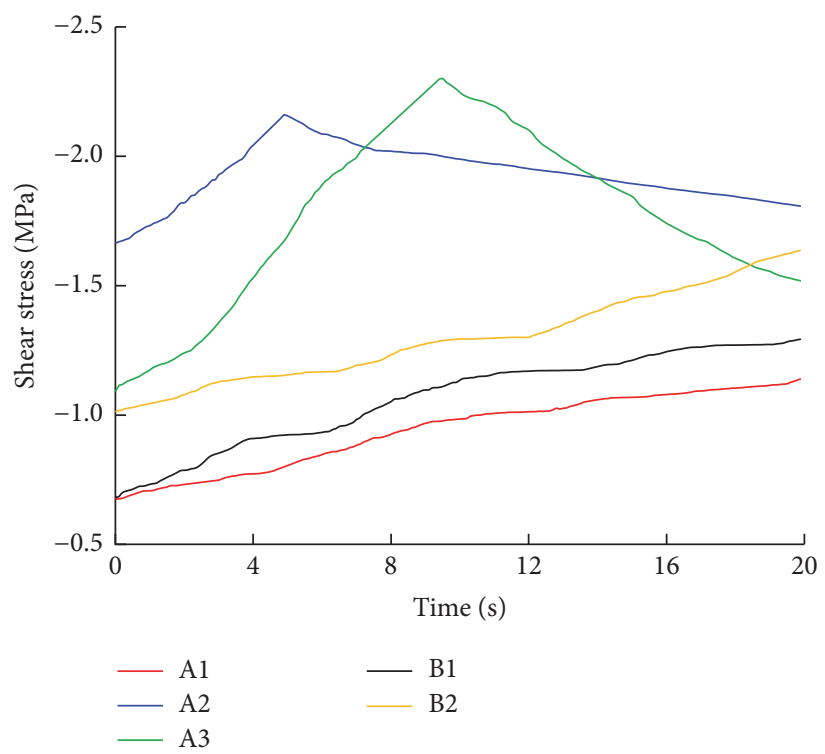

(b) Shear stress time-history at the anchor head

FIGURE 11: Stress time-history of the monitoring bolts.

values were larger. The neutral point positions of the bolts moved to the deep rock by $0-0.6 \mathrm{~m}$, which shows that the influence scope of the earthquake expanded gradually to the anchoring depth.

The normal stress of the bolts at the sidewalls in the main powerhouse was larger, and the length of the sections with normal stress values exceeding $200 \mathrm{MPa}$ reached $40-60 \%$ of the full length of the bolts. The damage length of the anchoring interface near the anchor head of the bolts at the sidewalls in the main powerhouse reached $0-0.3 \mathrm{~m}$, which shows that the earthquake disturbed the high sidewalls of the main powerhouse more considerably.

Figure 13 illustrates the maximal normal stress distribution of the bolts in the main powerhouse after the earthquake. At the upstream sidewall near the diversion tunnel and downstream sidewall near the tailrace tunnel, the normal stress 


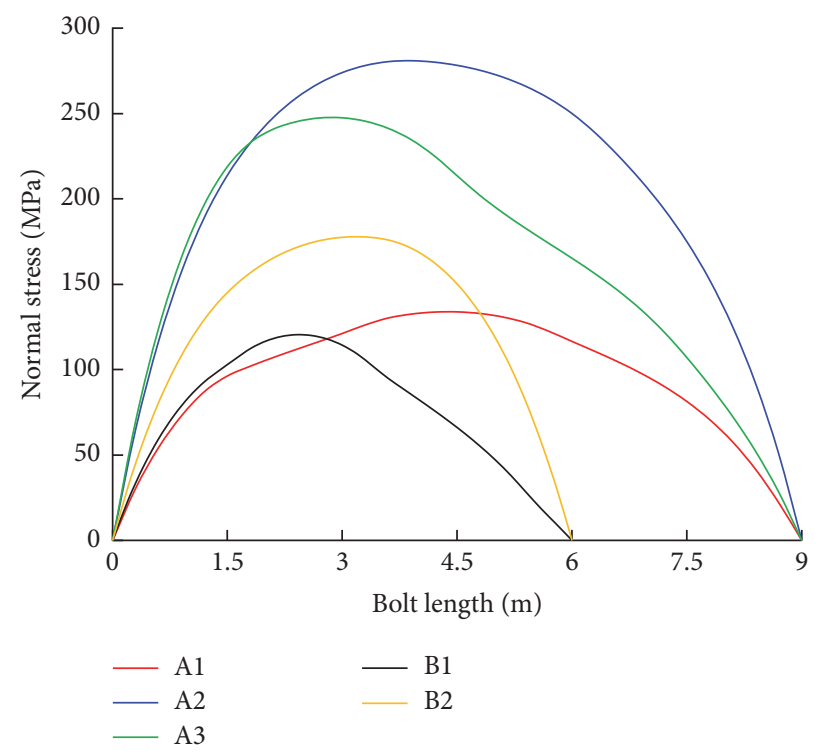

(a) Normal stress distributions of the bolts

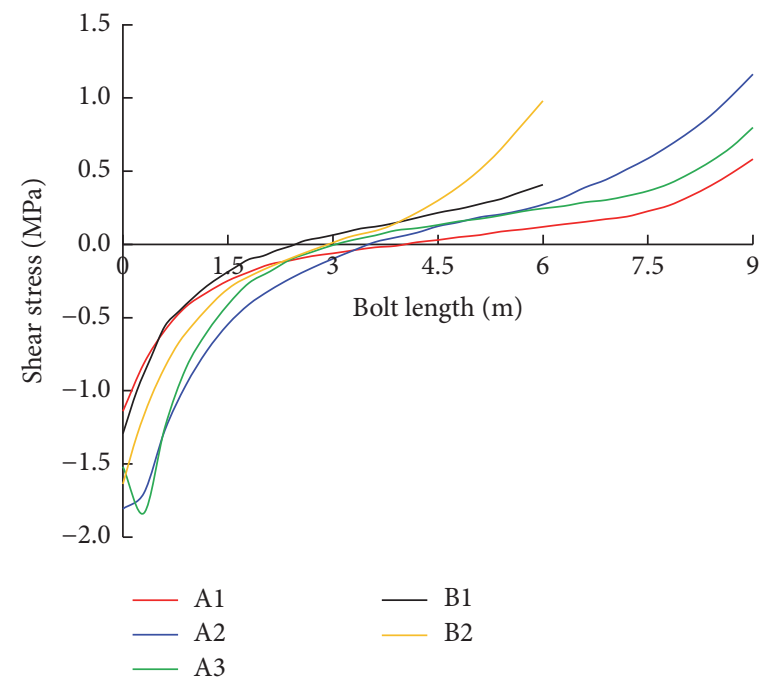

(b) Shear stress distributions of the anchoring interface

FIGURE 12: Stress distributions of the monitoring bolts (after the earthquake).

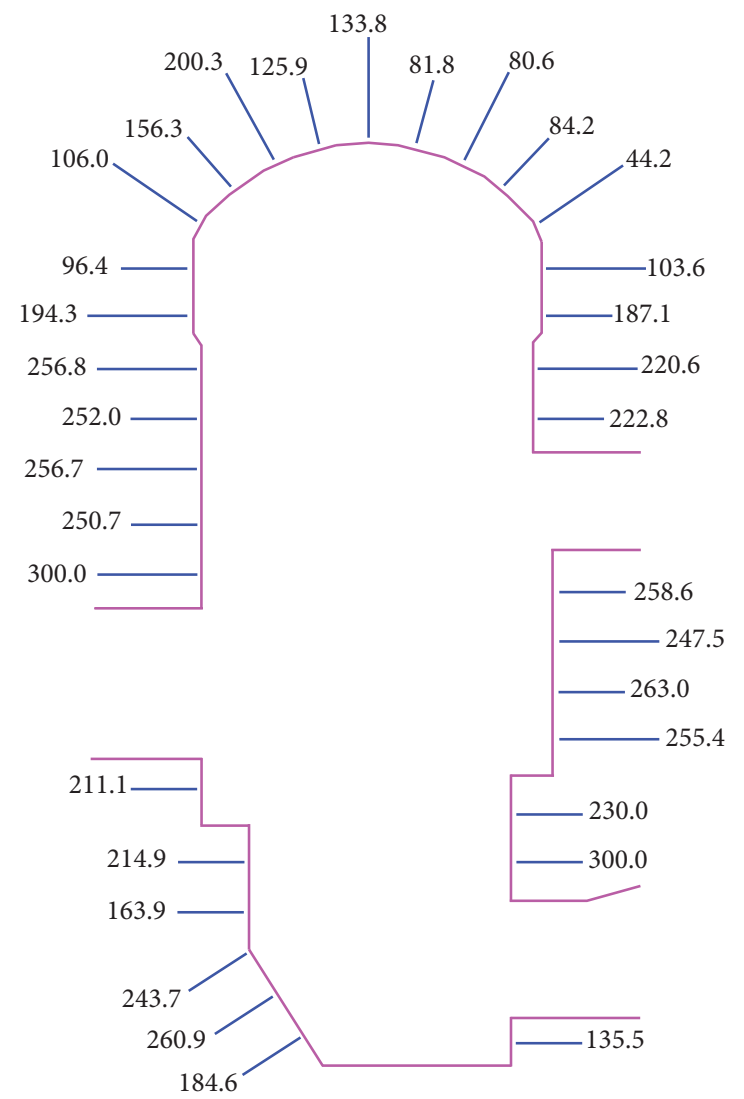

FIGURE 13: Maximal normal stress distribution of the bolts in the main powerhouse after the earthquake (unit: MPa).

values of a few bolts reached the yield strength $(300 \mathrm{MPa})$, and the yield length reached $1.5-3.0 \mathrm{~m}$, whereas the normal stress of the bolts at other positions was smaller.

Figure 14 shows the damage coefficient distribution of the anchoring interface at the anchor head in the main powerhouse after the earthquake. Many of the anchoring interfaces in the main powerhouse suffered damage. At the upstream sidewall near the diversion tunnel and downstream sidewall near the tailrace tunnel, the damage coefficient of the anchoring interface of a few bolts reached 1.0, indicating that 


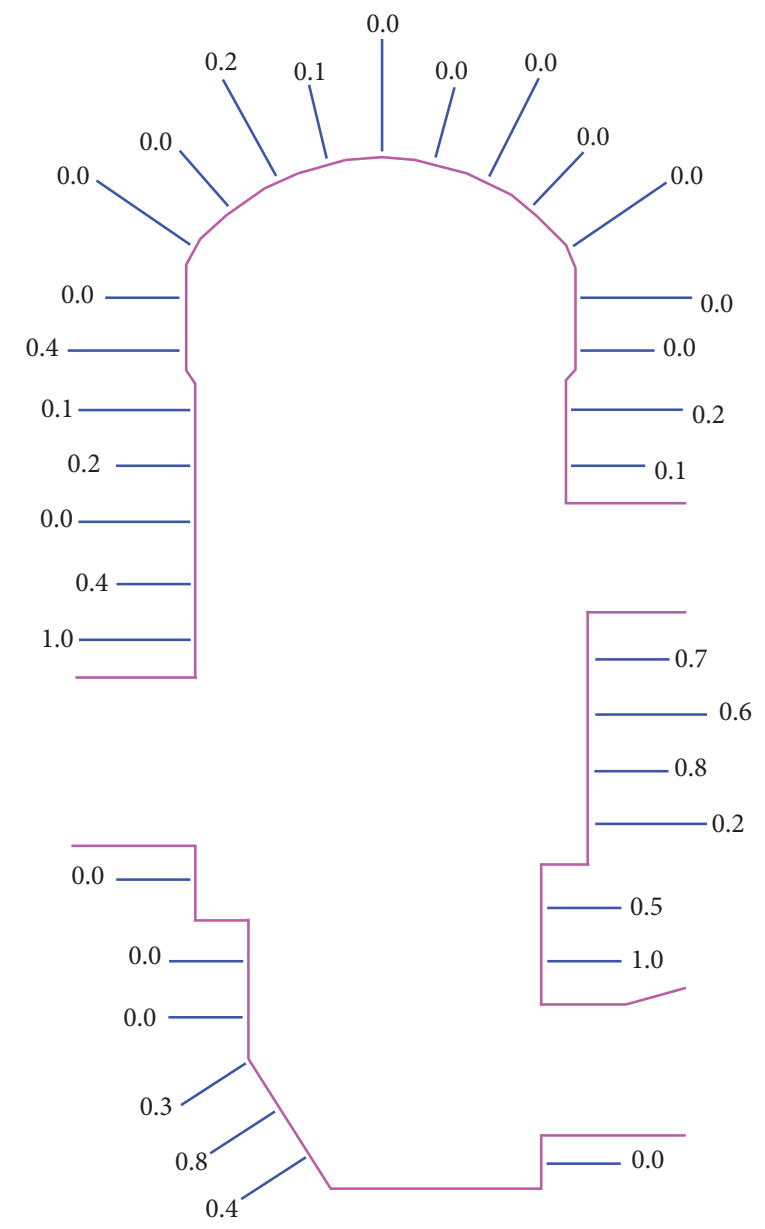

FIGURE 14: Damage coefficient distribution of the anchoring interface at the anchor head in the main powerhouse after the earthquake.

the anchoring interface was in a slip state. These positions should be reinforced to guarantee the antiseismic safety of the bolt support system. Once slip occurs at the anchor head, the slip position will gradually expand to the anchoring depth under the subsequent seismic load, which will negatively impact the force of the bolts.

\section{Conclusions}

This paper proposed a dynamic algorithm for bolts using the trilinear shear slip model based on the basic mechanical equations of the anchorage body. The following conclusions can be drawn from this study:

(1) It is feasible to simulate the force of the bolts in underground caverns under seismic loads using the bolt algorithm. The calculated stress distributions of the bolts corresponded well with the neutral point theory.

(2) It is effective to consider the shear damage on the anchoring interface because it can help reflect the damage evolution properties of the anchoring interface under seismic loads and can also provide new avenues for revealing the antiseismic failure mechanisms of the bolts in underground caverns.

(3) The normal stress of the bolts increases continuously during an earthquake, which may cause the bolts to yield. The shear stress of the anchoring interface at the anchor head increases rapidly; hence, this part is apt to be damaged or slip.

(4) The antiseismic safety evaluation of the bolt support system in underground caverns can be undertaken as a quantitative analysis of the bonding state of the anchoring interface and the material yield of the bolts. For this case study, a few bolts yielded, and the anchoring interface at the anchor head experienced slip at the upstream sidewall near the diversion tunnel and downstream sidewall near the tailrace tunnel in the main powerhouse. These positions should be the key zones for antiseismic support.

(5) This proposed algorithm mainly focused on the continuous contact state of the anchoring interface and ignored the discontinuity between the mortar and bolt, rock, or within mortar itself, which is helpful to simplify the dynamic finite element analysis. 
However, the discontinuity problem should be further researched to better study the interaction between the bolt and rock.

\section{Conflicts of Interest}

The authors declare that there are no conflicts of interest regarding the publication of this paper.

\section{Acknowledgments}

This study is supported by the National Key Basic Research Program of China (2015CB057904) and the National Natural Science Foundation of China (51279136 and 51579191). These supports are greatly acknowledged and appreciated.

\section{References}

[1] S. Ma, J. Nemcik, and N. Aziz, "An analytical model of fully grouted rock bolts subjected to tensile load," Construction and Building Materials, vol. 49, pp. 519-526, 2013.

[2] S. Ma, J. Nemcik, N. Aziz, and Z. Zhang, "Analytical model for rock bolts reaching free end slip," Construction and Building Materials, vol. 57, pp. 30-37, 2014.

[3] C. Cao, N. Jan, T. Ren, and A. Naj, "A study of rock bolting failure modes," International Journal of Mining Science and Technology, vol. 23, no. 1, pp. 79-88, 2013.

[4] J. Chen, S. Saydam, and P. C. Hagan, "An analytical model of the load transfer behavior of fully grouted cable bolts," Construction and Building Materials, vol. 101, pp. 1006-1015, 2015.

[5] L. B. Martín, M. Tijani, and F. Hadj-Hassen, "A new analytical solution to the mechanical behaviour of fully grouted rockbolts subjected to pull-out tests," Construction and Building Materials, vol. 25, no. 2, pp. 749-755, 2011.

[6] Q. Yang, X. Zhu, and M. Luan, "Development of hyperbolic model for fully grouting rock bolt and parameters analysis for anchoring effect," Chinese Journal of Rock Mechanics and Engineering, vol. 26, no. 4, pp. 692-698, 2007.

[7] M. Huang, Z. Zhou, and J. Ou, "Nonlinear analysis on load transfer mechanism of wholly grouted anchor rod along anchoring section," Chinese Journal of Rock Mechanics and Engineering, vol. 33, supplement 2, pp. 3992-3997, 2014.

[8] Y.-P. Luo, S. Shi, and Z.-X. Yan, "Shear interaction of anchorage body and rock and soil interface under the action of uplift load," Journal of the China Coal Society, vol. 40, no. 1, pp. 58-64, 2015.

[9] G. Rong, H. Zhu, and C. Zhou, "Testing study on working mechanism of fully grouted bolts of thread steel and smooth steel," Chinese Journal of Rock Mechanics and Engineering, vol. 23, no. 3, pp. 469-475, 2004.

[10] C.-A. You, M. Gao, L.-M. Zhang, Y.-B. Zhan, and J.-H. Wang, "Experimental research on stress distribution in anchorage body," Rock and Soil Mechanics, vol. 25, no. 1, pp. 63-66, 2004.

[11] B. Liu, D. Li, Y. Duan, G. Jin, and N. Tian, "Experimental study of bond-slip relationship between bolt and mortar and theoretical solution to failure process," Chinese Journal of Rock Mechanics and Engineering, vol. 30, no. 1, pp. 2790-2797, 2011.

[12] T. J. Freeman, "Behaviour of fully-bonded rock bolts in the kielder experimental tunnel," Tunnels Tunnelling, vol. 10, no. 5, pp. 37-40, 1978.
[13] M. S. Wang, X. R. He, and Y. T. Zhen, "The mechanics model and application of fully grouted rock bolt," Metal Mine, vol. 4, pp. 24-29, 1983.

[14] X. G. Zhu, Q. Yang, and M. T. Luan, "Study of reinforcement mechanics for fully grouting rock bolt in tunneling wall rock," Rock and Soil Mechanics, vol. 28, supplement 1, pp. 173-177, 2007.

[15] X.-C. Yao, N. Li, and Y.-S. Chen, "Theoretical solution for shear stresses on interface of fully grouted bolt in tunnels," Chinese Journal of Rock Mechanics and Engineering, vol. 24, no. 13, pp. 2272-2276, 2005.

[16] J.-Z. Wen, Y.-X. Zhang, and C. Wang, "Study of mechanical model of fully grouted rock bolt's anchorage interface in tunnel surrounding rock," Rock and Soil Mechanics, vol. 34, no. 6, pp. 1645-1651, 2013.

[17] Y. Cai, T. Esaki, and Y. Jiang, "An analytical model to predict axial load in grouted rock bolt for soft rock tunnelling," Tunnelling and Underground Space Technology, vol. 19, no. 6, pp. 607-618, 2004.

[18] Y. Cai, Y. Jiang, I. Djamaluddin, T. Iura, and T. Esaki, "An analytical model considering interaction behavior of grouted rock bolts for convergence-confinement method in tunneling design," International Journal of Rock Mechanics and Mining Sciences, vol. 76, pp. 112-126, 2015.

[19] Y. D. Xue, S. P. Zhang, and T. H. Kang, "Numerical analysis on dynamic response of rock bolts in mining roadways," Chinese Journal of Rock Mechanics and Engineering, vol. 22, no. 11, pp. 1903-1906, 2003.

[20] Z. Zhang and M. Xiao, "Simulation of anchor bolts by explicit 3D elastoplastic dynamic finite element method for underground caverns," Journal of Hydroelectric Engineering, vol. 31, no. 4, pp. 181-206, 2012.

[21] B. Benmokrane, A. Chennouf, and H. S. Mitri, "Laboratory evaluation of cement-based grouts and grouted rock anchors," International Journal of Rock Mechanics and Mining Sciences and, vol. 32, no. 7, pp. 633-642, 1995.

[22] H. Zhou, M. Xiao, and J.-T. Chen, "Study of anchoring mechanism and analysis of anchoring effect of fully grouted rock anchor in large-scale underground caverns," Rock and Soil Mechanics, vol. 37, no. 5, pp. 1503-1511, 2016.

[23] Z. G. Zhang, M. Xiao, and J. T. Chen, "Simulation of earthquake disaster process of large-scale underground caverns using three-dimensional dynamic finite element method," Chinese Journal of Rock Mechanics and Engineering, vol. 30, no. 3, pp. 509-523, 2011. 


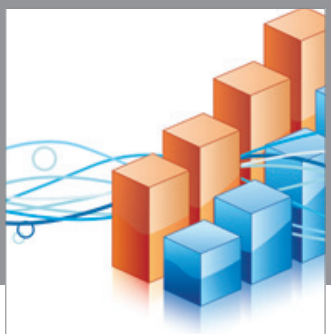

Advances in

Operations Research

vatem alat4

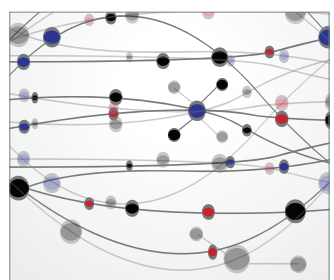

\section{The Scientific} World Journal
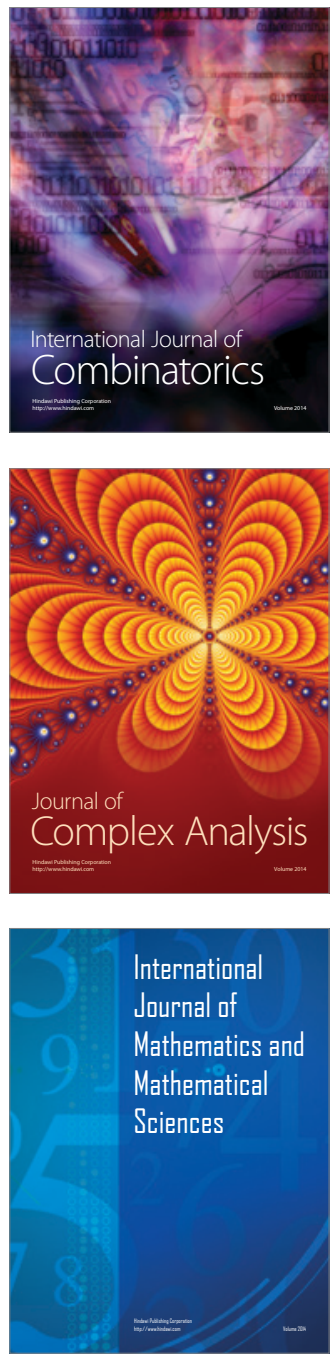
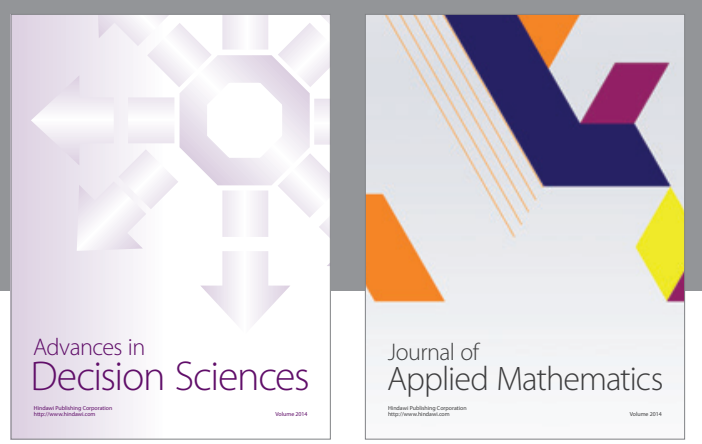

Algebra

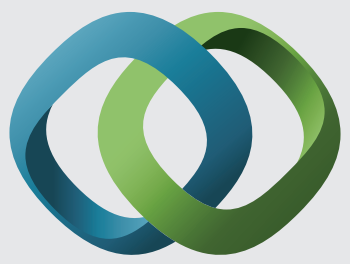

\section{Hindawi}

Submit your manuscripts at

https://www.hindawi.com
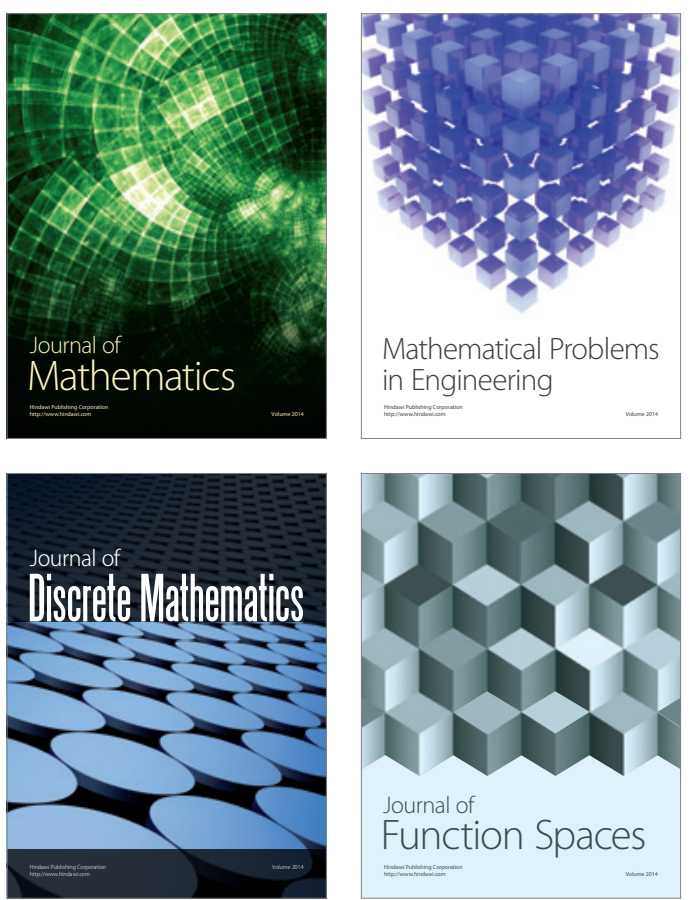

Mathematical Problems in Engineering
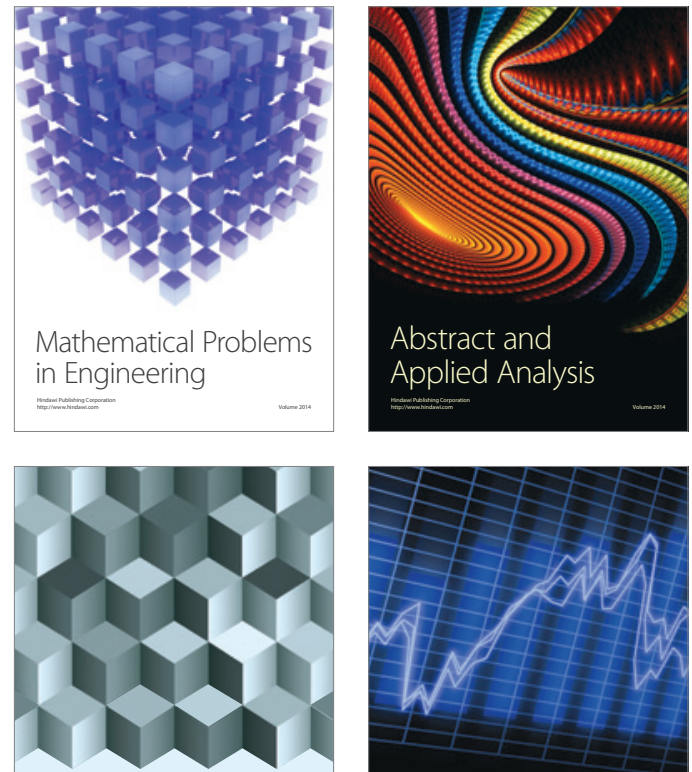

Journal of

Function Spaces

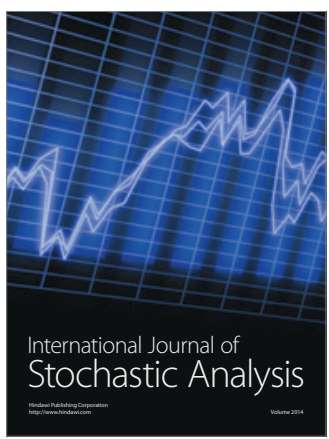

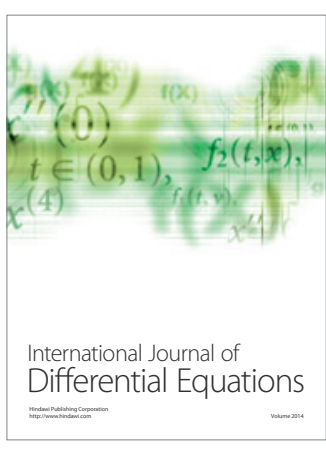
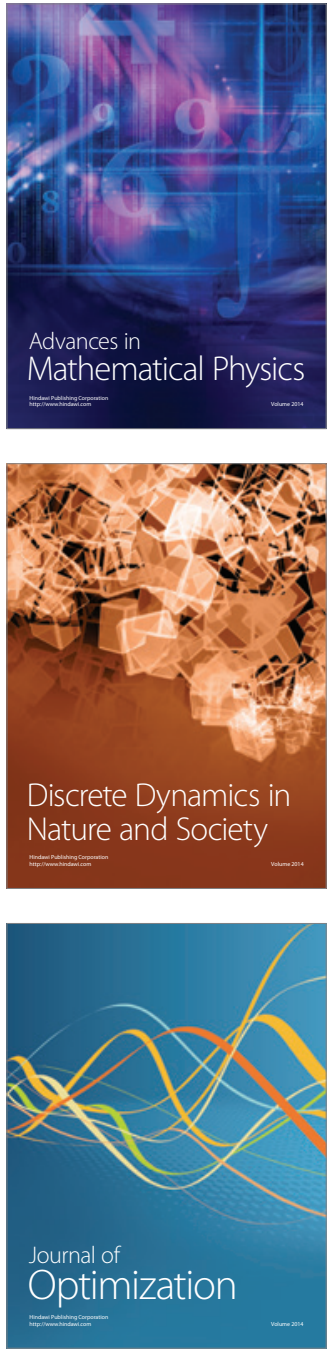